\title{
Development of a Perfusion Platform for Dynamic Cultivation of in vitro Skin Models
}

\author{
Kay Strüver ${ }^{\mathrm{a}}$ Wolfgang Friess $^{\mathrm{a}}$ Sarah Hedtrich $^{\mathrm{b}}$ \\ a Department of Pharmacy, Pharmaceutical Technology and Biopharmaceutics, Ludwig-Maximilians-Universität, \\ Munich, and ${ }^{\mathrm{b}}$ Institute for Pharmacy, Pharmacology, and Toxicology, Freie Universität Berlin, Berlin, Germany
}

\section{Keywords}

Skin models · Dynamic perfusion platform · Skin barrier function $\cdot$ Shear stress

\begin{abstract}
Reconstructed skin models are suitable test systems for toxicity testing and for basic investigations on (patho-)physiological aspects of human skin. Reconstructed human skin, however, has clear limitations such as the lack of immune cells and a significantly weaker skin barrier function compared to native human skin. Potential reasons for the latter might be the lack of mechanical forces during skin model cultivation which is performed classically in static well-plate setups. Mechanical forces and shear stress have a major impact on tissue formation and, hence, tissue engineering. In the present work, a perfusion platform was developed allowing dynamic cultivation of in vitro skin models. The platform was designed to cultivate reconstructed skin at the airliquid interface with a laminar and continuous medium flow below the dermis equivalent. Histological investigations confirmed the formation of a significantly thicker stratum corneum compared to the control cultivated under static
\end{abstract}

\section{KARGER}

(C) 2017 S. Karger AG, Basel

E-Mail karger@karger.com

www.karger.com/spp conditions. Moreover, the skin differentiation markers involucrin and filaggrin as well as the tight junction proteins claudin 1 and occludin showed increased expression in the dynamically cultured skin models. Unexpectedly, despite improved differentiation, the skin barrier function of the dynamically cultivated skin models was not enhanced compared with the skin models cultivated under static conditions.

(c) 2017 S. Karger AG, Basel

\section{Introduction}

Safety and risk assessment procedures for drugs and the demand to improve standards and knowledge about these topics goes along with constantly high numbers of animal experiments in the EU [1]. However, ethical standards of the modern society and low predictive power of animal models $[2,3]$ call for the avoidance or reduction of animal experiments whenever possible. Hence, academia and pharmaceutical industry are working on the establishment of alternative test systems in accordance with the 3 Rs principle established in 1959: the replace-

Prof. Dr. Sarah Hedtrich

Institute for Pharmacy, Pharmacology, and Toxicology Freie Universität Berlin, Königin-Luise-Str. 2-4 DE-14195 Berlin (Germany)

E-Mail sarah.hedtrich@fu-berlin.de 
ment, reduction or refinement of animal experiments. To bring in line the need for powerful test systems and the avoidance of animal experiments, alternative approaches, often based on tissue engineering, are investigated and improved [4, 5]. Especially for human skin, a whole slew of methods is available today.

Reconstructed human epidermis and full-thickness skin models are commercially available and validated by the OECD for skin irritation and corrosion testing. Additionally, they are accepted for testing skin absorption taking into account the generally higher permeability of in vitro skin models [6-8]. Moreover, skin models are used for the assessment of drugs' pharmacodynamics or side effects [9] and for fundamental studies on the (patho)physiological mechanism [10-12]. Nevertheless, in vitro skin models clearly have limitations compared to native human skin such as lower mechanical resistance, impaired maturation and differentiation, altered skin lipid composition and organization [13, 14], increased skin permeability [15] and a lack of complexity, e.g. missing immune cells or systemic circulation [16].

The reasons for the altered skin lipids and the weakened skin barrier function are diverse. All tissues in the human body are constantly subjected to forces such as pressure, fluid shear stress, stretch or compression. Mechanical forces are crucial for normal tissue homeostasis and remodeling and influence fundamental cellular events such as cell division [17-19]. These basic principles depict the importance of mechanical forces also for tissue engineering. Various publications have described beneficial effects of mechanical forces when applied on reconstructed tissue such as artificial cartilage or lung tissue [19-22]. Additionally, responses of human skin cells to electrical field stimulation, such as an accelerated alignment of fibroblasts, have been described [23]. Thus, the lack of specific biophysical and biochemical signaling or mechanical forces and shear stress during cultivation under static conditions in well plates may considerably contribute to the less efficient barrier function of skin models $[24,25]$. Furthermore, skin models do not have an active nutrient supply through capillaries; they lack the effect of convection and are dependent on nutrient supply by diffusion.

Hence, to improve the quality of in vitro skin models and to investigate the impact of mechanical forces on skin homeostasis, a perfused bioreactor was constructed allowing the cultivation of skin models at the air liquid interface and providing a continuous flow of cultivation medium at the basal side. Following the development of the bioreactor, optimized medium flow rates and veloci- ties were determined followed by analysis of their impact on skin differentiation and maturation; the expression of skin barrier and tight junction proteins was investigated, and the skin barrier function was determined.

\section{Materials and Methods}

\section{Construction of Perfusion Platform}

The perfusion platform was constructed for Falcon 6-well cell culture inserts (VWR, Darmstadt, Germany). The design drawing was performed using 3D CAD Design Software SolidWorks (Dassault Systèmes S.A., Vélizy-Villacoublay, France). The test systems were manufactured at the research workshop of the Faculty of Chemistry and Pharmacy, LMU Munich. The platform is composed of polytetrafluoroethylene (PTFE) to allow steam sterilization.

\section{Cell Culture}

Primary human fibroblasts and keratinocytes were isolated from juvenile foreskin according to standard procedures (approved by the ethics committee of the LMU Munich, with written consent) [26]. Briefly, epidermis and dermis were separated after overnight incubation with Dispase II (1.2 U/mL in PBS; Roche Diagnostics, Mannheim, Germany). The separated epidermis was treated with trypsin/EDTA (2.5 mg/mL trypsin, $1 \mathrm{mmmol} / \mathrm{L}$ EDTA; Biochrome, Berlin, Germany) for $5 \mathrm{~min}$ at $37^{\circ} \mathrm{C}$ to singularize keratinocytes. To cultivate primary keratinocytes, keratinocyte growth medium (Lonza, Cologne, Germany) was used. After outgrowth from the dermis, fibroblasts were further cultivated in DMEM (Sigma-Aldrich, Taufkirchen, Germany) containing $5 \mathrm{mM}$ L-glutamine and $10 \%$ FBS (Biochrome, Berlin, Germany). Media were changed every other day, and the cells were used at passage 2 or 3 .

\section{Construction of Skin Models}

In vitro skin models were generated according to previously published procedures $[27,28]$. Briefly, bovine collagen $(3 \mathrm{mg} / \mathrm{mL}$, Cellsytems, Troisdorf, Germany) was mixed with 10-fold Hanks balanced salt solution (Thermo Scientific, Darmstadt, Germany) and brought to neutral $\mathrm{pH}$. Afterwards, $2.5 \times 10^{5}$ fibroblasts (per skin model) were added, and $2.5 \mathrm{~mL}$ of the mixture was poured into 6-well cell culture inserts (pore size: $3 \mu \mathrm{m}$, surface area $4.2 \mathrm{~cm}^{2}, 2 \times$ $10^{6}$ pores $/ \mathrm{cm}^{2}$, PET membrane; VWR, Ismaning, Germany). After solidification at $37^{\circ} \mathrm{C}$ for $2 \mathrm{~h}, 4.2 \times 10^{6}$ normal keratinocytes were added on top of the collagen matrix. $24 \mathrm{~h}$ later, the skin models were lifted to the air-liquid interface, and the medium was changed to a differentiation medium. At this stage, the skin models were transferred to the perfusion platform and grown for 6 more days. Skin models cultivated in static 6 -well plates served as reference.

\section{Hematoxylin-Eosin Staining}

Skin models were punched and immediately embedded in tissue-freezing medium (Leica Microsystems, Nussloch, Germany). The embedded models were shock-frozen using liquid nitrogen and stored for $12 \mathrm{~h}$ at $-80^{\circ} \mathrm{C}$. Vertical $7-\mu \mathrm{m}$-thick cryosections (at an angle of $90^{\circ}$ ) were prepared using a cryotome (Leica Microsystems). A standard hematoxylin-eosin staining procedure was performed for histological analysis. The skin sections were analyzed using the microscope BZ-8000 (Keyence, Neu-Isenburg, Germany).
A Perfusion Platform for Dynamic Cultivation of in vitro Skin Models
Skin Pharmacol Physiol 2017;30:180-189 DOI: $10.1159 / 000476071$ 

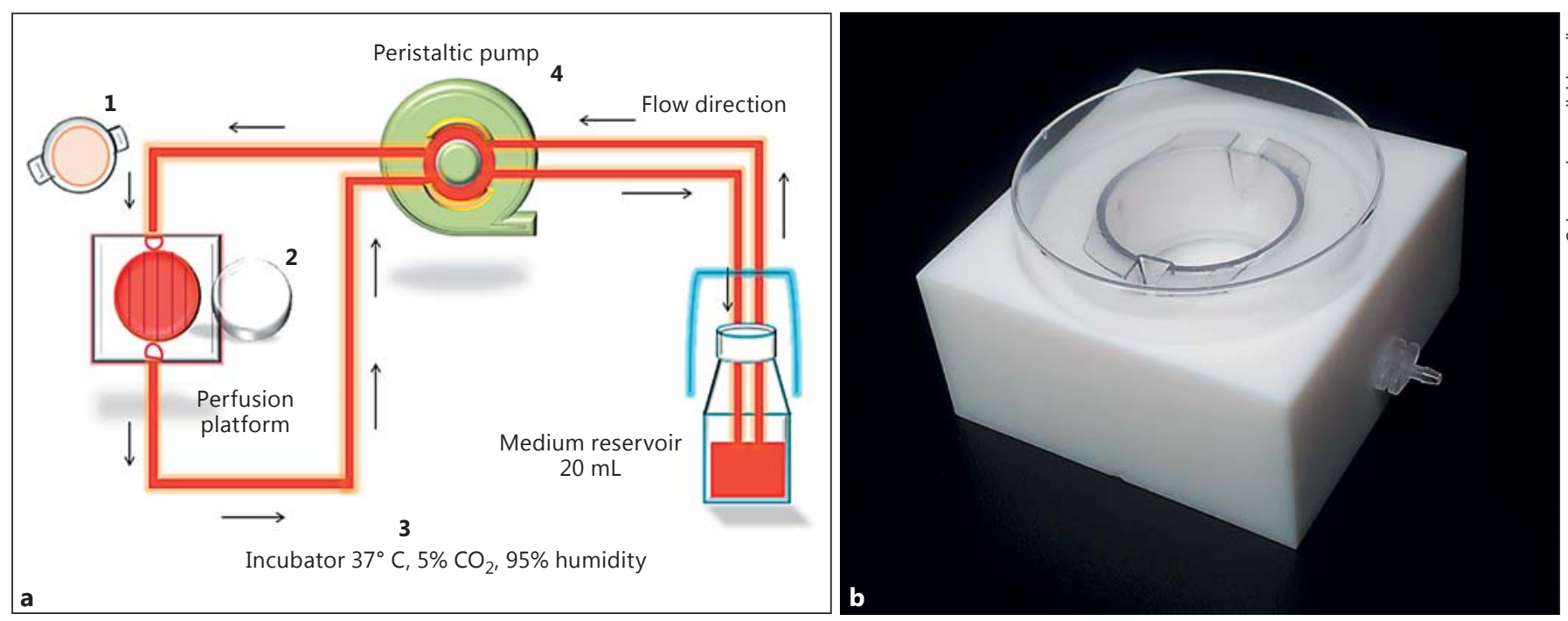

Fig. 1. a Scheme of the perfusion bioreactor: (1) transfer of the skin models in the cell culture inserts into the perfusion platform after performing the air lift at day 1 of tissue cultivation; (2) capping of the platform; (3) transfer of the entire setup into the incubator at

$37^{\circ} \mathrm{C}, 5 \% \mathrm{CO}_{2}$ and $95 \%$ humidity until day 7 of tissue cultivation; (4) peristaltic pump for continuous flow of the skin model differentiation medium. b Image of the perfusion platform equipped with cell culture insert, lid, and tubing connectors.

Table 1. Primer sequences for PCR

\begin{tabular}{lll}
\hline Gene & Primer sense $5^{\prime}-3^{\prime}$ & Primer antisense $5^{\prime}-3^{\prime}$ \\
\hline$Y W H A Z$ & AGACGGAAGGTGCTGAGAAA & GAAGCATTGGGGATCAAGAA \\
$F L G$ & AAGGAACTTCTGGAAAAGGAATTTC & TTGTGGTCTATATCCAAGTGATCCAT \\
$I V L$ & TCCTCCAGTCAATACCCATCAG & CAGCAGTCATGTGCTTTTCCT \\
$C L D N-1$ & GCGCGATATTTCTTCTTGCAGG & TTCGTACCTGGCATTGACTGG \\
$O C L N$ & TGCATGTTCGACCAATGC & AAGCCACTTCCTCCATAAGG \\
\hline
\end{tabular}

\section{Thickness Measurements}

The thickness of the stratum corneum was measured from the top of the skin models to the beginning of the viable epidermis, directly below the stratum corneum. Viable epidermal thickness was measured from below the stratum corneum to the beginning of the dermal equivalent in 3 hematoxylin-eosin-stained sections (per skin equivalent). Dermal thickness measurement was performed from the beginning of the dermis equivalent to the beginning of the cell culture insert. In total, 10 measuring points were evaluated in each section using BZ image analysis software, respectively (Keyence).

\section{Real-Time Polymerase Chain Reaction}

Skin models were punched to discs of $10-\mathrm{mm}$ diameter. The epidermis was peeled-off and immediately frozen in liquid nitrogen. The frozen epidermis was subsequently milled with a CryoMill (RETSCH GmbH, Haan, Germany). RNA was isolated using the NucleoSpin ${ }^{\circledR}$ RNA II kit (Macherey-Nagel, Düren, Germany) according to the manufacturer's instructions. RNA was treated with DNase 1 (Sigma-Aldrich, Taufkirchen, Germany). For cDNA synthesis, RevertAidTM First Strand cDNA Synthesis Kit (Thermo Scientific, Waltham, MA, USA) was used. For relative gene expression quantification, quantitative polymerase chain reaction (PCR) was performed using the Power SYBR ${ }^{\circledR}$ Green PCR Master Mix (Thermo Scientific, Darmstadt, Germany) and the qTower 2.2 PCR cycler (Analytik Jena AG, Jena, Germany). The primer sequences (Tib Molbiol, Berlin, Germany) are listed in Table 1. YWHAZ served as the housekeeping gene.

\section{Western Blot}

For Western blot analysis of filaggrin, involucrin, claudin 1, and occludin, the epidermis of skin models was shock frozen in liquid nitrogen and milled using a CryoMill (Retsch $\mathrm{GmbH}$, Haan, Germany). The milled epidermis was then lysed in RIPA buffer containing protease inhibitors (New England Biolabs, Frankfurt/Main, Germany), centrifuged for $30 \mathrm{~min}$ at $14,000 \mathrm{~g}$, and the supernatant was subsequently stored at $-80^{\circ} \mathrm{C}$ until use. The protein amount was quantified by a BCA protein assay (Thermo Scientific, Waltham, MA, USA). $30 \mu \mathrm{g}$ of each protein sample was incubated at $95^{\circ} \mathrm{C}$ in standard SDS-PAGE buffer and 
separated via $10 \%$ SDS polyacrylamide gel electrophoresis (BioRad, Munich, Germany). Gels were blotted onto Immobilon P nitrocellulose membranes (Carl Roth, Karlsruhe, Germany) via Trans-Blot ${ }^{\circledR}$ Turbo ${ }^{\mathrm{TM}}$ Transfer System (Bio-Rad). After blocking with 5\% nonfat dry milk in tris-buffered saline-Tween $20(0.1 \%)$ for $1 \mathrm{~h}$, the membranes were incubated with primary antibodies (anti-filaggrin antibody ab81468, anti-involucrin ab53112; Abcam, Cambridge, UK; CLDN1 monoclonal antibody [clone 1C5D9], OCLN monoclonal antibody [clone 1G7]; Abnova, Taipei, Taiwan) overnight. Subsequently, the membranes were washed and incubated with anti-rabbit or anti-mouse horseradish-peroxidase-conjugated secondary antibody (Cell Signaling, Frankfurt/Main, Germany) at room temperature for $1 \mathrm{~h}$. All blots were developed with SignalFire ${ }^{\mathrm{TM}}$ ECL reagent (Cell Signaling) and visualized by a PXi/PXi Touch gel imaging system (Syngene, Cambridge, UK). Protein expression was semiquantified by densitometry and normalized to $\beta$-actin levels using Image $J$ version 1.6 (National Institutes of Health, Bethesda, MD, USA).

\section{Skin Permeability Testing}

The permeability of the skin models was evaluated according to validated test procedures [8]. Briefly, stock solutions of testosterone $\left(40 \mu \mathrm{g} / \mathrm{mL}, 2 \%[\mathrm{v} / \mathrm{v}]\right.$ Igepal ${ }^{\circledR}$ CA-630) and caffeine $(1 \mathrm{mg} /$ $\mathrm{mL}$ ) were spiked with an appropriate amount of the radiolabeled compound to achieve a total radioactivity of $2 \mu \mathrm{Ci} / \mathrm{mL}$. Permeation studies were performed at day 7 of tissue cultivation using a Franz diffusion cell setup (diameter $15 \mathrm{~mm}$, volume $12 \mathrm{~mL}$; Permegear, Bethlehem, PA, USA).

\section{Statistical Analysis}

The data were statistically analyzed using ANOVA and onesample or two-sample $t$ test. $p \leq 0.05$ was defined as the level of significance.

\section{Results}

\section{Setup and Establishment of a Perfused Bioreactor}

In a first step, a perfusion platform was constructed, where standard 6-well inserts fit in (Fig. 1). To ensure a laminar and continuous flow of the cultivation medium, the perfusion platform was equipped with 2 orifices to connect with the tubing. From the orifices, the medium got distributed by a hemicycle deepening and was transported in a laminar flow by introducing parallel channels into the PTFE platform right underneath the cell culture insert membrane. To ensure that the amount of medium entering the platform is identical with the amount which leaves the platform, both orifices were connected to the same peristaltic pump by silicon tubing ending in the medium reservoir (Fig. 1a).

\section{Histological Analysis}

Following establishment of the perfusion platform, different medium flow rates were applied, ranging from

A Perfusion Platform for Dynamic Cultivation of in vitro Skin Models
1.25 to $10 \mathrm{~mL} / \mathrm{h}$ (Fig. 2). In general, all dynamically cultivated skin models developed a significantly thicker stratum corneum, the keratinocytes aligned to the direction of medium flow, and a significantly thinner but more compact dermis equivalent was observed (Fig. 2, 3). No significant differences in epidermal maturation or differentiation were observed (Fig. 2). The viable epidermis showed similar dimensions for all flow rates compared to the static control model.

\section{Gene and Protein Expression of Skin Barrier and}

Tight Junction Proteins following Dynamic Tissue

\section{Cultivation}

Western blot analysis revealed higher expression of the intermediate and late-stage skin differentiation markers involucrin and filaggrin, indicating improved epidermal differentiation as well as increased expression of the tight junction proteins occludin and claudin 1 in the dynamically cultivated skin models (Fig. 4). Unexpectedly, cultivation at $7.5 \mathrm{ml} / \mathrm{h}$ showed a trend towards reduced expression of involucrin and occludin (Fig. 4b, d). On mRNA level, there was a clear trend towards reduced expression of filaggrin, involucrin, claudin 1 , and occludin after cultivation at $7.5 \mathrm{~mL} / \mathrm{h}$ (Fig. 5).

\section{Skin Permeability Studies}

To assess the barrier function of the skin models and potential positive effects of dynamic culture condition, skin absorption studies using the OECD reference substances testosterone and caffeine were performed. The testosterone flux was significantly increased in the skin models cultivated in the perfusion platforms (Fig. 6a; Table 2). No difference in skin permeability between statically or dynamically cultured skin models was detected for the more hydrophilic test compound caffeine (Fig. 6b).

Fig. 2. Representative histological pictures of a skin model cultivated under static condition (a), in the perfusion platform with a flow rate of $1.25 \mathrm{~mL} / \mathrm{h}(\mathbf{b})$, flow rate of $2.5 \mathrm{~mL} / \mathrm{h}(\mathbf{c})$, or flow rate $7.5 \mathrm{~mL} / \mathrm{h}$ (d) after 7 days of cultivation. SC, stratum corneum; VE, viable epidermis; $\mathrm{D}$, dermis. Magnification $\times 20$.

Fig. 3. a Thickness of the stratum corneum after skin model cultivation of 7 days under static conditions or in the perfusion platform with flow rates of $1.25 \mathrm{~mL} / \mathrm{h}, 2.5 \mathrm{~L} / \mathrm{h}$, or $7.5 \mathrm{~mL} / \mathrm{h}$. b Thickness of the stratum corneum (SC), viable epidermis (VE), and dermis (D) after skin model cultivation of 7 days under static conditions or in the perfusion platform with flow rates of 1.25 $\mathrm{mL} / \mathrm{h}, 2.5 \mathrm{~L} / \mathrm{h}$, or $7.5 \mathrm{~mL} / \mathrm{h}$. Data are presented as mean $\pm \mathrm{SEM}$; $n=4 ;{ }^{*} p \leq 0.05,{ }^{* *} p \leq 0.01,{ }^{* * *} p \leq 0.005$.

(For figures see next page.)

Skin Pharmacol Physiol 2017;30:180-189 

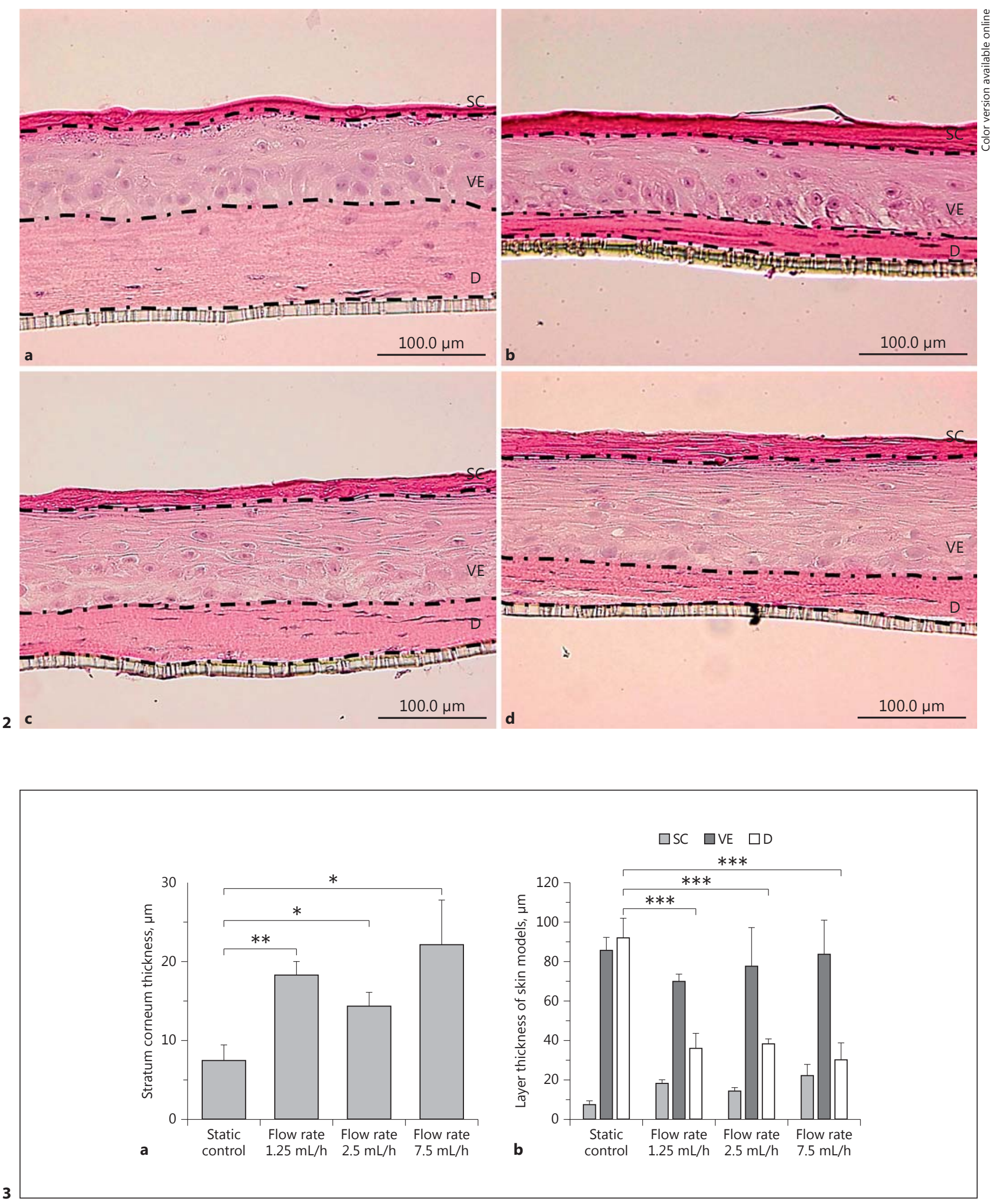


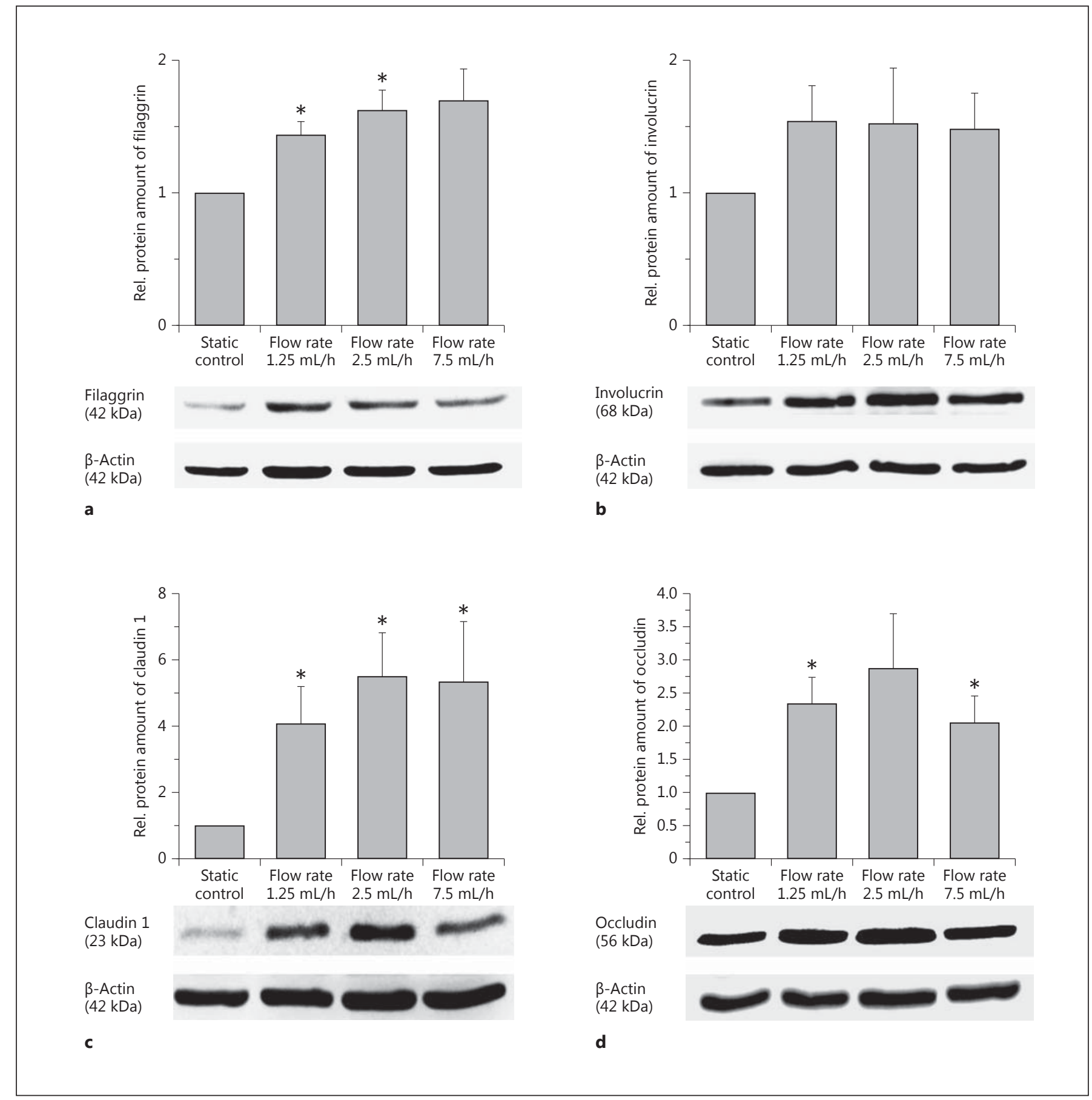

Fig. 4. Impact of tissue cultivation in the perfusion platform on the protein expression of filaggrin (a), involucrin (b), claudin 1 (c), and occludin (d) after 7 days of cultivation. Western blots and relative protein expression were semiquantified by densitometry. Data are presented as mean \pm SEM; $n=4 ;{ }^{*} p \leq 0.05$. 

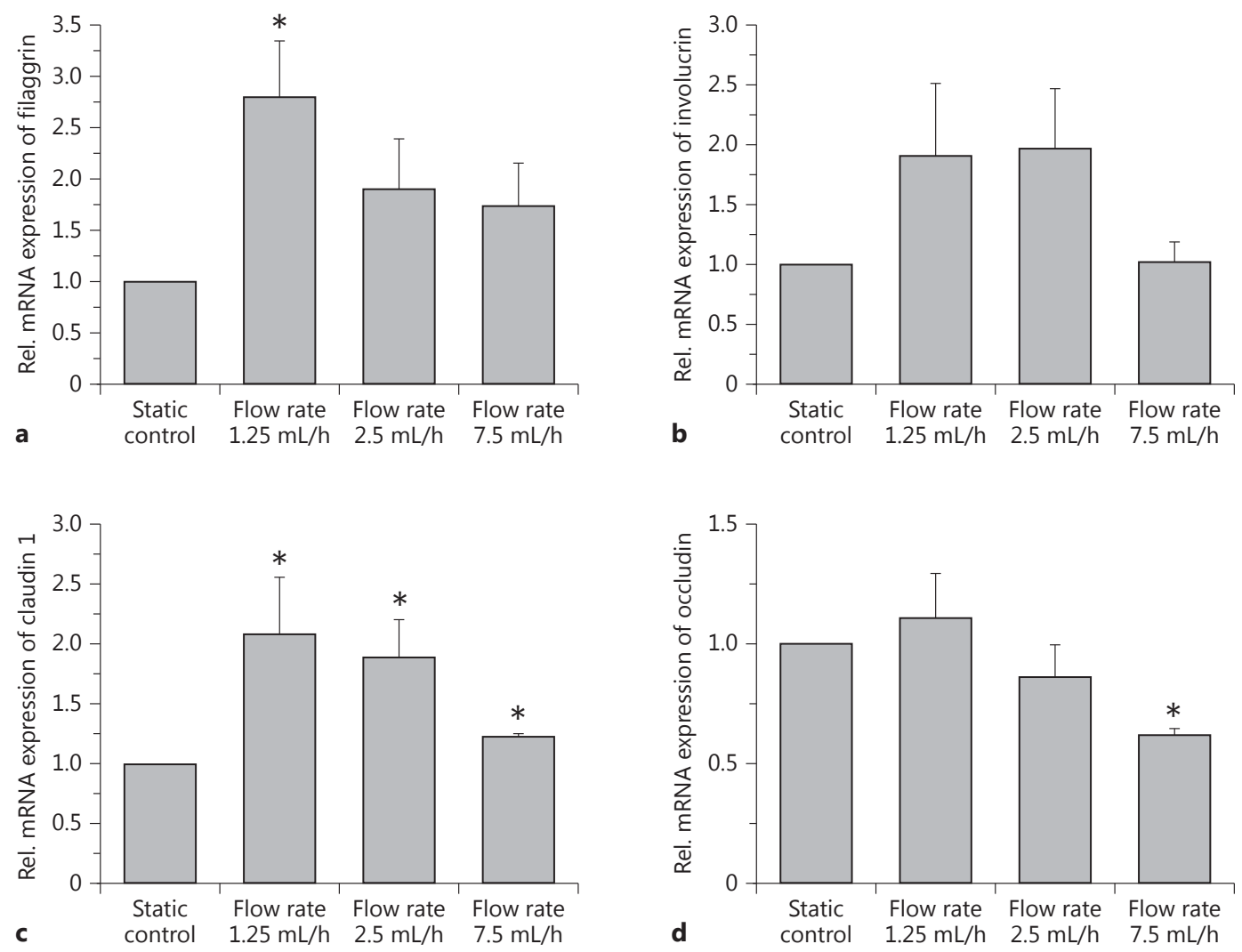

Fig. 5. Relative mRNA expression of filaggrin (a), involucrin (b), claudin 1 (c), and occludin (d) in skin models cultivated for 7 days under static or dynamic conditions. Data are presented as mean \pm SEM; $n=4$; $^{*} p \leq 0.05$.
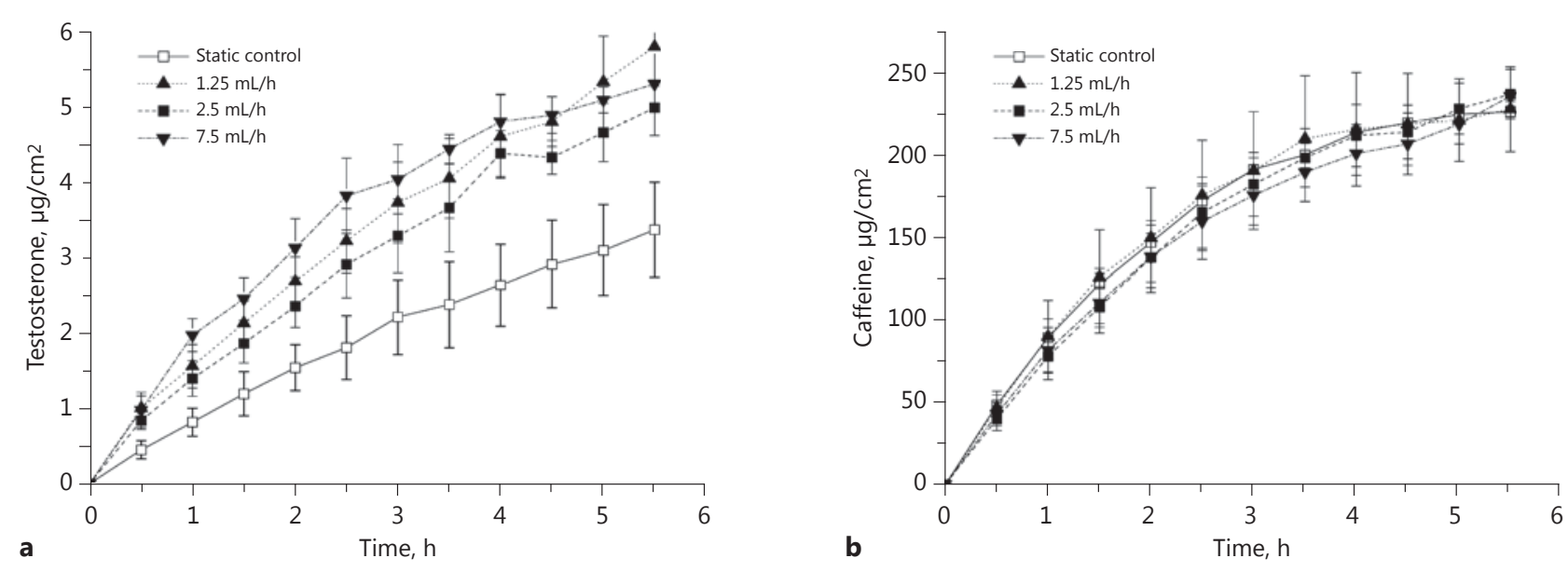

Fig. 6. Cumulative amounts (mean $\pm \mathrm{SEM}, n=3$ ) of radioactively labeled permeated testosterone (a) and caffeine (b) following topical application on skin models cultivated under static control or dynamic $(1.25,2.5,7.5 \mathrm{~mL} / \mathrm{h})$ conditions. 
Table 2. Apparent permeability coefficient $\left(\mathrm{P}_{\mathrm{app}}, \mathrm{cm} / \mathrm{s}\right)$ of radioactively labeled testosterone and caffeine (mean $\pm \mathrm{SD}, n=3$ )

\begin{tabular}{lllll}
\hline $\mathrm{P}_{\text {app }}$ & Static control & $1.25 \mathrm{~mL} / \mathrm{h}$ & $2.5 \mathrm{~mL} / \mathrm{h}$ & $7.5 \mathrm{~mL} / \mathrm{h}$ \\
\hline Testosterone & $4.0 \pm 1.8 \times 10^{-6}$ & $8.4 \pm 1.3 \times 10^{-6}$ & $7.5 \pm 1.0 \times 10^{-6}$ & $9.4 \pm 2.2 \times 10^{-6}$ \\
Caffeine & $4.4 \pm 0.2 \times 10^{-4}$ & $4.4 \pm 1.3 \times 10^{-4}$ & $4.3 \pm 0.7 \times 10^{-4}$ & $4.4 \pm 0.8 \times 10^{-4}$ \\
\hline
\end{tabular}

\section{Discussion}

Over the past 20 years, the interest in reconstructed human skin has constantly been growing since in vitro skin models enable the reduction and replacement of animal experiments and help to avoid interspecies-related differences which are major reasons for the often discussed low predictive power of animal models [3, 29]. Although the versatility of skin models is widely recognized today, skin models still have clear limitations such as increased permeability compared to native human skin [15, $30,31]$. This drawback may result from nonphysiological cell culture medium, a lack of cellular crosstalk or tissue complexity and/or tissue cultivation under static conditions in well-plates.

Since the impact of shear stress and mechanical forces on tissue homeostasis and regeneration in vivo and in vitro is well established $[17,32,33]$, we constructed a PTFEbased perfusion platform enabling continuous flow of skin model differentiation medium underneath the skin model. Following construction of the skin models in well plates, they were transferred to the perfusion platform at day 1 of tissue cultivation and were further cultivated under dynamic conditions for 7 days. At first, the impact of the flow rate on skin model differentiation and maturation was investigated. Clear detrimental effects on epidermal differentiation resulted from the highest flow rate of $10 \mathrm{~mL} / \mathrm{h}$ which was therefore excluded from further studies (data not shown). Slower flow velocities between 1.25 and $7.5 \mathrm{~mL} / \mathrm{h}$ resulted in a significant thickening of the stratum corneum. This effect was comparable to previously published data, where the maintenance of the EpiDermFT skin model in a dynamic setup led to a more pronounced stratum corneum compared to the static control [24]. Additionally, higher compaction of the dermis equivalent was observed likely due to detachment of collagen gel as a result of the media flux.

Moreover, we observed significantly increased expression of the important skin barrier protein and differentiation marker filaggrin and a clear trend for increased

A Perfusion Platform for Dynamic Cultivation of in vitro Skin Models involucrin expression following dynamic tissue cultivation (Fig. 4). Filaggrin is an important structural protein which contributes to the integrity of the epidermal barrier and the alignment of keratin bundles $[34,35]$ and is disturbed in common skin diseases such as atopic dermatitis [36]. The intermediate-stage differentiation marker involucrin is part of the cornified envelope and reinforces the skin barrier [37]. Interestingly, a trend for reduced mRNA and protein expression was observed for cultivation at $7.5 \mathrm{~mL} / \mathrm{h}$ flow rate, which may indicate detrimental effects of high velocities on skin differentiation and demonstrates the importance of flow rate adjustment. In line with the epidermal barrier proteins, claudin 1 and occludin expression was increased after dynamic tissue cultivation. Again, slightly reduced expression was observed for the models cultivated at $7.5 \mathrm{~mL} / \mathrm{h}$.

Based on the positive effects of the dynamic setting on skin differentiation and maturation, an improved barrier function of dynamically cultivated skin models was expected. Surprisingly, no improved skin barrier function was determined. An even increased permeability was determined for the lipophilic test compound testosterone in the dynamically cultured skin models in contrast to the static cultures. This stands in contrast to the significantly thicker stratum corneum as well as the increased expression of epidermal and tight junction proteins in the dynamically cultivated skin models. One can speculate about potential reasons such as detrimental effects of shear stress on the skin lipid organization or detrimental impact of the collagen detachment from the dermis equivalent, but this requires further evaluation. Interestingly, improved epidermal differentiation is clearly achieved (Fig. 4). Potential explanations, which need to be investigated further, are, for example, an increased release of specific growth factors as a direct result from the shear stress or improved nutrient supply due to introducing active mass transfer by convection as previously demonstrated in hollow fiber membranes used for graft cell cultivation or blood cell oxygenators [38-40]. Overall, our data once more highlight the complex setting of skin

Skin Pharmacol Physiol 2017;30:180-189 187 
physiology and are first indications that simple perfusion of skin models might be not sufficient to improve the skin barrier function.

\section{Acknowledgements}

The authors would like to thank Ramona Kleeberger (Technical University Munich) for the assistance with the histological analysis of the skin models.

\section{Statement of Ethics}

The standard procedures to isolate primary human fibroblasts and keratinocytes from juvenile foreskin were approved by the Ethics Committee of the LMU Munich.

\section{Disclosure Statement}

The authors state no conflict of interest.

\section{References}

1 European Commission: Seventh Report on the Statistics on the Number of Animals used for Experimental and other Scientific Purposes in the Member States of the European Union. Brussels, European Commission, 2013.

2 Seok J, Warren HS, Cuenca AG, Mindrinos $\mathrm{MN}$, Baker $\mathrm{H} \mathrm{V}, \mathrm{Xu} \mathrm{W}$, et al: Genomic responses in mouse models poorly mimic human inflammatory diseases. Proc Natl Acad Sci USA 2013;110:3507-3512.

3 Perrin S: Preclinical research: make mouse studies work. Nature 2014;507:423-425.

4 de Vries RBM, Leenaars M, Tra J, Huijbregtse $\mathrm{R}$, Bongers E, Jansen JA, et al: The potential of tissue engineering for developing alternatives to animal experiments: a systematic review. J Tissue Eng Regen Med 2015;9:771-778.

5 Reisinger K, Hoffmann S, Alépée N, Ashikaga $\mathrm{T}$, Barroso J, Elcombe C, et al: Systematic evaluation of non-animal test methods for skin sensitisation safety assessment. Toxicol Vitr 2015;29:259-272.

6 OECD: OECD Guideline No. 431 for the Testing of Chemicals: in vitro Skin Corrosion: Reconstructed Human Epidermis (RhE) Test Method. Paris, OECD, 2004

7 OECD: OECD Guideline No. 439 for the Testing of Chemicals: in vitro Skin Irritation: Reconstructed Human Epidermis Test Method. Paris, OECD, 2010.

8 OECD: OECD Guideline No. 428 for the Testing of Chemicals: Skin Absorption: in vitro Method. Paris, OECD, 2004

9 Zöller NN, Kippenberger S, Thaçi D, Mewes K, Spiegel M, Sättler A, et al: Evaluation of beneficial and adverse effects of glucocorticoids on a newly developed full-thickness skin model. Toxicol In Vitro 2008;22:747-759.

10 Hönzke S, Wallmeyer L, Ostrowski A, Radbruch M, Mundhenk L, Schäfer-Korting M, et al: Influence of Th2 cytokines on the cornified envelope, tight junction proteins, and $\beta$-defensins in filaggrin-deficient skin equivalents. J Invest Dermatol 2016;136:631-639.
11 van Drongelen V, Haisma EM, Out-Luiting JJ, Nibbering PH, El Ghalbzouri A: Reduced filaggrin expression is accompanied by increased Staphylococcus aureus colonization of epidermal skin models. Clin Exp Allergy 2014;44:1515-1524.

12 Berroth A, Kühnl J, Kurschat N, Schwarz A, Stäb F, Schwarz T, et al: Role of fibroblasts in the pathogenesis of atopic dermatitis. J Allergy Clin Immunol 2013;131:1547-1554.

13 Ponec M, Boelsma E, Gibbs S, Mommaas M: Characterization of reconstructed skin models. Skin Pharmacol Appl Skin Physiol 2002; 15(suppl 1):4-17.

14 Vávrová K, Henkes D, Strüver K, Sochorová M, Skolová B, Witting MY, et al: Filaggrin deficiency leads to impaired lipid profile and altered acidification pathways in a $3 \mathrm{D}$ skin construct. J Invest Dermatol 2014;134:746-753.

15 Schäfer-Korting M, Bock U, Diembeck W, Düsing H-J, Gamer A, Haltner-Ukomadu E, et al: The use of reconstructed human epidermis for skin absorption testing: results of the validation study. Altern Lab Anim 2008;36: 161-187.

16 Küchler S, Strüver K, Friess W: Reconstructed skin models as emerging tools for drug absorption studies. Expert Opin Drug Metab Toxicol 2013;9:1255-1263

17 Shiu Y-T: Mechanical forces on cells; in Bronzino JD (ed): Tissue Engineering and Artificial Organs. Boca Raton, CRC Press, Taylor \& Francis Group, 2006

18 Hronik-Tupaj M, Kaplan DL: A review of the responses of two- and three-dimensional engineered tissues to electric fields. Tissue Eng B Rev 2012;18:167-180.

19 Huh D, Matthews BD, Mammoto A, Montoya-Zavala M, Hsin HY, Ingber DE: Reconstituting organ-level lung functions on a chip. Science 2010;328:1662-1668.

20 Ingber DE: Tensegrity II. How structural networks influence cellular information processing networks. J Cell Sci 2003;116:1397-1408.
21 Davisson T, Kunig S, Chen A, Sah R, Ratcliffe A: Static and dynamic compression modulate matrix metabolism in tissue engineered cartilage. J Orthop Res 2002;20:842-848.

22 Zhang X, Wang X, Keshav V, Wang X, Johanas JT, Leisk GG, et al: Dynamic culture conditions to generate silk-based tissue-engineered vascular grafts. Biomaterials 2009;30: 3213-3223.

23 Hronik-Tupaj M, Kaplan DL: A review of the responses of two- and three-dimensional engineered tissues to electric fields. Tissue Eng B Rev 2012;18:167-180.

24 Ataç B, Wagner I, Horland R, Lauster R, Marx U, Tonevitsky AG, et al: Skin and hair on-achip: in vitro skin models versus ex vivo tissue maintenance with dynamic perfusion. Lab Chip 2013;13:3555-3561.

25 Griffith LG, Swartz MA: Capturing complex 3D tissue physiology in vitro. Nat Rev $\mathrm{Mol}$ Cell Biol 2006;7:211-224.

26 Gysler A, Lange K, Korting HC, SchäferKorting M: Prednicarbate biotransformation in human foreskin keratinocytes and fibroblasts. Pharm Res 1997;14:793-797.

27 Eckl K-M, Alef T, Torres S, Hennies HC: Fullthickness human skin models for congenital ichthyosis and related keratinization disorders. J Invest Dermatol 2011;131:1938-1942.

28 Küchler S, Henkes D, Eckl K-M, Ackermann $\mathrm{K}$, Plendl J, Korting H-C, et al: Hallmarks of atopic skin mimicked in vitro by means of a skin disease model based on FLG knockdown. Altern Lab Anim 2011;39:471-480.

29 Leist M, Hartung T: Inflammatory findings on species extrapolations: humans are definitely no $70-\mathrm{kg}$ mice. Arch Toxicol 2013;87: 563-567.

30 Ponec M: Skin constructs for replacement of skin tissues for in vitro testing. Adv Drug Deliv Rev 2002;54(suppl 1):S19-S30.

31 van Smeden J, Boiten WA, Hankemeier T, Rissmann R, Bouwstra JA, Vreeken RJ: Combined LC/MS-platform for analysis of all major stratum corneum lipids, and the profiling of skin substitutes. Biochim Biophys Acta 2014:1841:70-79. 
32 Mammoto T, Ingber DE: Mechanical control of tissue and organ development. Development 2010;137:1407-1420.

33 Mammoto $A$, Mammoto $\mathrm{T}$, Ingber $\mathrm{DE}$ : Mechanosensitive mechanisms in transcriptional regulation. J Cell Sci 2012;125:30613073.

34 Proksch E, Brandner JM, Jensen JM: The skin: an indispensable barrier. Exp Dermatol 2008; 17:1063-1072.
35 McAleer MA, Irvine AD: The multifunctional role of filaggrin in allergic skin disease. J Allergy Clin Immunol 2013;131:280-291.

36 Cabanillas B, Novak N: Atopic dermatitis and filaggrin. Curr Opin Immunol 2016;42:1-8.

37 Candi E, Schmidt R, Melino G: The cornified envelope: a model of cell death in the skin. Nat Rev Mol Cell Biol 2005;6:328-340.

38 Nagy E, Hadik P: Analysis of mass transfer in hollow-fiber membranes. Desalination 2002; 145:147-152.
39 Wickramasinghe SR, Garcia JD, Han B: Mass and momentum transfer in hollow fibre blood oxygenators. J Memb Sci 2002;208:247-256.

40 Bridge MJ, Broadhead KW, Hitchcock RW, Webb K, Tresco PA: A simple instrument to characterize convective and diffusive transport of single hollow fibers of short length. J Memb Sci 2001;183:223-233. 